\title{
Congenital Nephrotic Syndrome of the Finnish Type: A Greek Case Report
}

\author{
Sofia Melina Stasinou1,2, George Valasoulis, Ioannis Georgiou ${ }^{3}$, Kyrgiou Maria ${ }^{4}$, \\ Evangelos Paraskevaidis', Nikolaos Plachouras ${ }^{1}$ \\ ${ }^{1}$ Department of Obstetrics \& Gynaecology, University Hospital of Ioannina, loannina, Greece \\ ${ }^{2}$ Create Health Clinic, London, UK \\ ${ }^{3}$ Genetics and IVF Unit, Department of Obstetrics \& Gynaecology, University Hospital of loannina, Ioannina, \\ Greece \\ ${ }^{4}$ Queen Charlotte's and Chelsea Hospital Hammersmith, London, UK \\ Email: m.stasinou@yahoo.com
}

Received 28 April 2014; revised 3 June 2014; accepted 10 June 2014

Copyright (C) 2014 by authors and Scientific Research Publishing Inc.

This work is licensed under the Creative Commons Attribution International License (CC BY).

http://creativecommons.org/licenses/by/4.0/

(c) (i) Open Access

\begin{abstract}
Congenital Nephrotic Syndrome Type 1 (Congenital Nephrotic Syndrome of the Finnish Type-CNF) is an autosomal recessive disorder encoding by nephrin gene mutation which is a (transmembrane protein 1-homolog-NPHS1) structural component of the slit diaphragm responsible for the proper functioning of the renal filtration barrier. In NPHS1 kidneys there is an effacement of the foot processes of the podocytes and impaired glomerular filtration barrier leading to antenatal manifestations and end-renal stage of disease after birth. We present a case of this disease where sonographic appearance of the fetal kidneys had alerted the experts for further genetic investigation for congenital nephrotic syndrome.
\end{abstract}

\section{Keywords}

NPHS1 Gene, Congenital Nephrotic Syndrome, Kidney Ultrasound Findings

\section{Introduction}

Congenital Nephrotic Syndrome of the Finnish Type (CNF) is inherited in an autosomal recessive manner with the same incidence in both sexes and has been observed in all countries and races, with the highest incidence in Finnish population (approximately 1/10,000 neonates) [1]. The main cause of the CNF syndrome is a loss-offunction mutation into the gene encoding nephrin (transmembrane protein 1-homolog-NPHS1), a major podocyte protein. The NPHS1 gene is located in chromosomal region 19q13.1. The most frequent mutations of 
NPHS1 described in the literature, are [2]: 1) The "Fin-Major" group of carriers (2-bp deletion in exon-2) and 2) the "Fin-Minor" group (a mutation in exon-26) [3] [4]. Both the mutations lead to the same podocytes damage [2] [5] [6].

This paper reports a case of CNF presented to our Department of Obstetrics with abnormal findings at 24 weeks gestation scan.

\section{Case Report}

A 27-year-old Greek woman was referred to the Department of Obstetrics of Ioannina University Hospital, at 24 weeks of gestation. She had one term delivery with a healthy child and free obstetric history. None of the parents had Finnish ancestry. The first trimester screening had been performed at her local district hospital and the measurements of the crown-rump length (CRL), the thickness of nuchal translucency (NT = $1.8 \mathrm{~mm}<2.5 \mathrm{~mm}$ ) and the maternal serum-biochemical markers, in association with her age, had placed the pregnancy at low risk group for fetal chromosomal abnormalities.

The ultrasound scan was performed by an accredited doctor with a subspecialty in Fetal Medicine Ultrasound revealing at that time enlarged and hyperechogenic kidneys with a cystic appearance bilaterally (Figure $1 \&$ Figure 2). The growth measurements including amniotic fluid volume and the grade of the placenta were according to the gestational age (24 weeks).

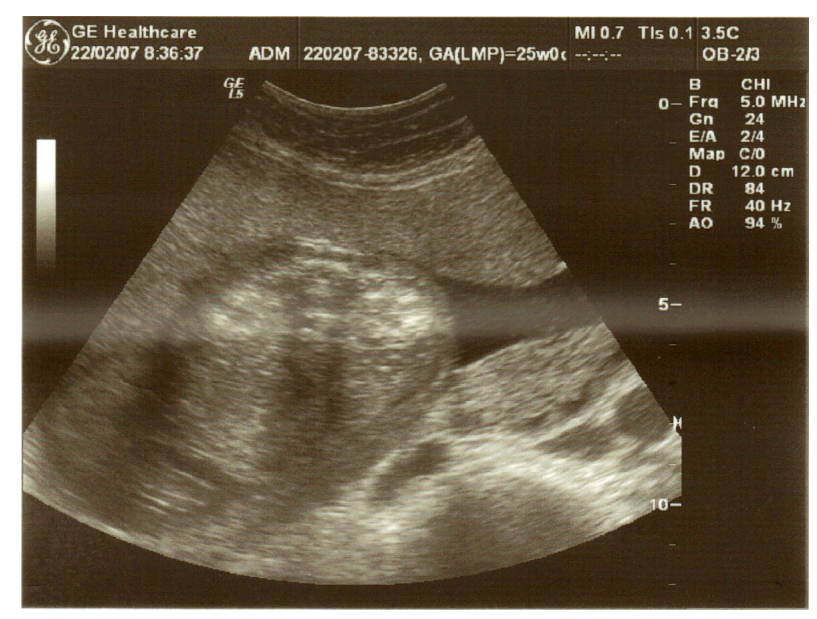

Figure 1. Transverse section in utero at 25 weeks' gestation. Both fetal kidneys have parenchymal hyperechogenicity.

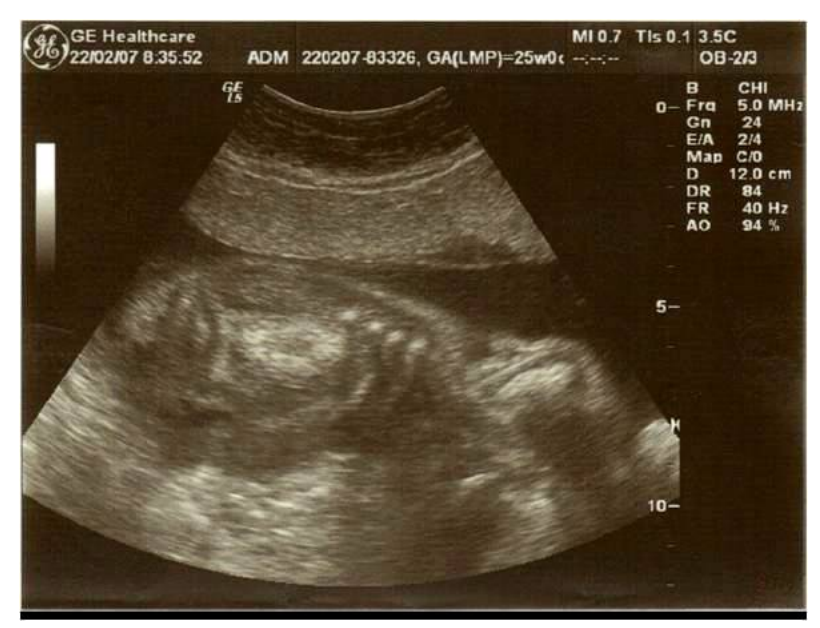

Figure 2. Longitudinal view of the fetal kidneys in utero at 25 weeks' gestation. 
The persistence of the sonographic findings in the next follow-up scans enhanced the clinical suspicion of renal genetic syndrome. The couple had been informed widely about the risks and they made a decision at that point to continue with the pregnancy. The clinical meeting decision was to proceed with the genetic confirmation of the possible disorder. Blood samples were obtained from both the parents and the fetus by omphalocentesis and have been sent through a laboratory Network, called GENDIA (for GENetic DIAgnostics), currently consisting of more than 50 laboratories. GENDIA is supported by a diagnostic medical lab (AML) based in Antwerp in Belgium. Subsequently, PCR-technique confirmed the inherited NPHS1 mutation and further action was taken with the pregnancy termination.

\section{Discussion}

The filtration-barrier of the kidney is composed of three layers: 1) the basal membrane, 2) the fenestrated endothelium and 3) the podocytes layer with extensive foot processes [6] [7]. Under normal conditions, a slit diaphragm is interposed between the podocytes, permitting only water and small plasma solutes pass through the barrier [7]. Nephrin, as a podocyte protein, is located at the glomerular slit diaphragm of the kidney connecting podocyte foot processes in the glomerular capillary wall.

In NPHS1 kidneys the extensive effacement of the podocytes foot processes is already evident during fetal life [6], so the symptoms appear at the time of birth or during the first three months of the newborn's life, where a rapid progression to glomerular and tubulointerstitial fibrosis and end-stage renal disease is developing. The impaired glomerular filtration leads to a heavy-proteinuria, hypoproteinemia, generalized oedema, ascites, hyperlipidemia, hyper-coagulopathy and recurrent neonatal bacterial infections [8].

Albumin infusions and intravenous antibiotics administration, seems to be necessary before nephrectomy(unilateral or bilateral), as the CNF syndrome appears to be resistant to conservative management with steroids and immunosuppressive drugs. It is accepted that, early peritoneal dialysis before the development of renal failure can be helpful, in terms of controlling massive protein loss. Kidney transplantation when the neonate reaches a body weight of 8 - $9 \mathrm{Kg}$, is the only curative treatment modality [2] [9].

Antenatal manifestations of the syndrome include placental thickness ( $>25 \%$ of the newborn weight), prematurity and low fetal weight at birth. Increased alpha-fetoprotein (AFP) levels, in fetal and maternal serum, have been used for years for prenatal diagnosis of CNF, due to in-utero proteinuria. The recommendation of repeat amniotic fluid AFP measurements before the $20^{\text {th }}$ gestational week, cannot be used as a specific prenatal diagnostic marker for CNF, as this seems to be a temporary increase [7] [9]. Therefore, genetic testing is the only acceptable and precise diagnostic approach for CNF.

Furthermore, hyperechogenic kidneys are a classic but non-specific finding, in differential diagnosis among other disorders. Conversely, the detection of hyperechogenic, enlarged kidneys in combination with a thick placenta and intrauterine growth retardation should suggest but not confirm the diagnosis of CNF [1] [7] [10].

In the present case report the only assessed abnormal finding, was the sonographic appearance of the kidneys at the $24^{\text {th }}$ week of gestation. Although, the contribution of ultrasound is described widely as a non-specific examination for detecting such a congenital disorder, the observation of abnormal kidneys structure, may alert the obstetricians for further investigation of those cases. Subsequently, the recognition of enlarged and hyperechogenic kidneys with microcystic appearance bilaterally may be the first finding that prompts a further fetal and maternal work-up in order to identify CNF through genetic processes.

\section{Bulleted Points}

- $\mathrm{CNF}$ is an autosomal recessive disorder;

- A gene mutation encoding nephrin (NPHS1) is the main cause of the particular disorder;

- In NPHS1 kidneys there is an effacement of the foot processes of the podocytes and impaired glomerular filtration barrier leading to antenatal manifestations and end-renal disease after birth;

- Abnormal findings in ultrasound (hyperechoic, enlarged, microcysistic kideneys) may alert the experts for further genetic investigation of CNF.

\section{References}

[1] Northrup, M., Mendez-Castillo, A., Brown, J.C., Frazier, S. and Luger, A.M. (2003) Congenital Nephrotic Syndrome, Finnish Type: Sonographic Appearance and Pathologic Correlation. Journal of Ultrasound in Medicine, 22, 1097- 
1099.

[2] Kestila, M., Lenkkeri, U., Mannikko, M., Lamerdin, J., McCready, P., Putaala, H., et al. (1998) Positionally Cloned Gene for a Novel Glomerular Protein-Nephrin-Is Mutated in Congenital Nephrotic Syndrome. Molecular Cell, 1, 575-582. http://dx.doi.org/10.1016/S1097-2765(00)80057-X

[3] Koziell, A., Grech, V., Hussain, S., Lee, G., Lenkkeri, U., Tryggvason, K., et al. (2002) Genotype/Phenotype Correlations of NPHS1 and NPHS2 Mutations in Nephrotic Syndrome Advocate a Functional Inter-Relationship in Glomerular Filtration. Human Molecular Genetics, 11, 379-388. http://dx.doi.org/10.1093/hmg/11.4.379

[4] Lenkkeri, U., Mannikko, M., McCready, P., Lamerdin, J., Gribouval, O., Niaudet, P.M., et al. (1999) Structure of the Gene for Congenital Nephrotic Syndrome of the Finnish Type (NPHS1) and Characterization of Mutations. American Journal of Human Genetics, 64, 51-61. http://dx.doi.org/10.1086/302182

[5] Patrakka, J., Kestila, M., Wartiovaara, J., Ruotsalainen, V., Tissari, P., Lenkkeri, U., et al. (2000) Congenital Nephrotic Syndrome (NPHS1): Features Resulting from Different Mutations in Finnish Patients. Kidney International, 58, 972 980. http://dx.doi.org/10.1046/j.1523-1755.2000.00254.x

[6] Patrakka, J., Martin, P., Salonen, R., Kestila, M., Ruotsalainen, V., Mannikko, M., et al. (2002) Proteinuria and Prenatal Diagnosis of Congenital Nephrosis in Fetal Carriers of Nephrin Gene Mutations. Lancet, 359, 1575-1577. http://dx.doi.org/10.1016/S0140-6736(02)08504-5

[7] Avni, E.F., Vandenhoute, K., Devriendt, A., Ismaili, K., Hackx, M., Janssen, F., et al. (2011) Update on Congenital Nephrotic Syndromes and the Contribution of US. Pediatric Radiology, 41, 76-81. http://dx.doi.org/10.1007/s00247-010-1793-5

[8] Kuusniemi, A.M., Merenmies, J., Lahdenkari, A.T., Holmberg, C., Salmela, K., Karikoski, R., et al. (2006) Glomerular Sclerosis in Kidneys with Congenital Nephrotic Syndrome (NPHS1). Kidney International, 70, 1423-1431. http://dx.doi.org/10.1038/sj.ki.5001779

[9] Beltcheva, O., Martin, P., Lenkkeri, U. and Tryggvason, K. (2001) Mutation Spectrum in the Nephrin Gene (NPHS1) in Congenital Nephrotic Syndrome. Human Mutation, 17, 368-373. http://dx.doi.org/10.1002/humu.1111

[10] Salame, H., Damry, N., Vandenhoudt, K., Hall, M. and Avni, F.E. (2003) The Contribution of Ultrasound for the Differential Diagnosis of Congenital and Infantile Nephrotic Syndrome. European Radiology, 13, 2674-2679. http://dx.doi.org/10.1007/s00330-003-1920-x 
Scientific Research Publishing (SCIRP) is one of the largest Open Access journal publishers. It is currently publishing more than 200 open access, online, peer-reviewed journals covering a wide range of academic disciplines. SCIRP serves the worldwide academic communities and contributes to the progress and application of science with its publication.

Other selected journals from SCIRP are listed as below. Submit your manuscript to us via either submit@scirp.org or Online Submission Portal.
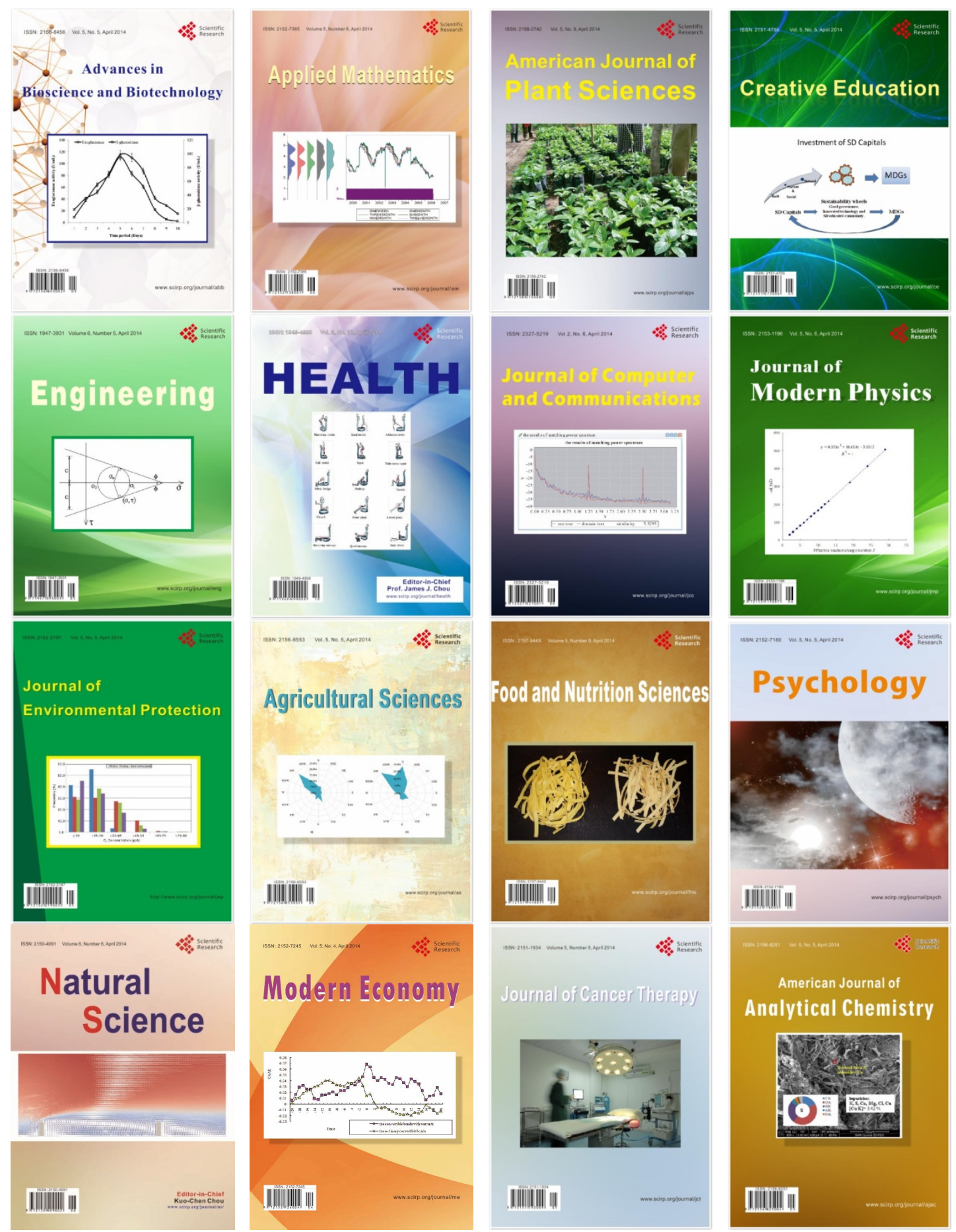